\title{
Effects of Nordic Walking on Gait Symmetry in Mild Parkinson's Disease
}

\author{
Ana Paula J. Zanardi ${ }^{1}$, Flávia G. Martinez ${ }^{1}$, Edson S. da Silva ${ }^{1}$, Marcela Z. Casal ${ }^{1}$ (D), \\ Valéria F. Martins ${ }^{1}$, Elren Passos-Monteiro ${ }^{1,2}$, Aline N. Haas ${ }^{1}$ \\ and Leonardo A. Peyré-Tartaruga $1, *$ \\ 1 Exercise Research Laboratory, School of Physical Education, Physical Therapy and Dance, \\ Universidade Federal do Rio Grande do Sul, Porto Alegre 90000-000, Brazil; \\ anapjzanardi@gmail.com (A.P.J.Z.); flavia.martinez@ufrgs.br (F.G.M.); \\ edsonsoaressilva@hotmail.com (E.S.d.S.); marcelazcasal@gmail.com (M.Z.C.); valeria.feijo@ufrgs.br (V.F.M.); \\ elren.monteiro@gmail.com (E.P.-M.); jhham5969@naver.com (A.N.H.) \\ 2 Laboratory of Locomotion PhysioMechanics, Faculty of Physical Education, Universidade Federal do Pará, \\ Castanhal 68740-000, Brazil \\ * Correspondence: leonardo.tartaruga@ufrgs.br; Tel.: +55-51984063793
}

Received: 30 September 2019; Accepted: 2 December 2019; Published: 4 December 2019

\begin{abstract}
Individuals with Parkinson's disease (PD) have gait asymmetries, and exercise therapy may reduce the differences between more and less affected limbs. The Nordic walking (NW) training may contribute to reducing the asymmetry in upper and lower limb movements in people with PD. We compared the effects of 11 weeks of NW aerobic training on asymmetrical variables of gait in subjects with mild PD. Fourteen subjects with idiopathic PD, age: $66.8 \pm 9.6$ years, and Hoehn and Yard stage of 1.5 points were enrolled. The kinematic analysis was performed pre and post-intervention. Data were collected at two randomized walking speeds $\left(0.28 \mathrm{~m} \cdot \mathrm{s}^{-1}\right.$ and $\left.0.83 \mathrm{~m} \cdot \mathrm{s}^{-1}\right)$ during five minutes on the treadmill without poles. The more affected and less affected body side symmetries (threshold at $5 \%$ between sides) of angular kinematics and spatiotemporal gait parameters were calculated. We used Generalized Estimating Equations with Bonferroni post hoc $(\alpha=0.05)$. Maximal flexion of the knee $(p=0.007)$ and maximal abduction of the hip $(p=0.041)$ were asymmetrical pre and became symmetrical post NW intervention. The differences occurred in the knee was less affected and the hip was more affected. We concluded that 11 weeks of NW training promoted similarities in gait parameters and improved knee and hip angular parameters for PD subjects.
\end{abstract}

Keywords: locomotion; biomechanics; pole walking; more affected side; asymmetries; angles; spatiotemporal; aerobic training

\section{Introduction}

Individuals with Parkinson's disease (PD) walk slower than able-bodied people. The lower segmental and trunk excursion are associated with a reduced stride length and increased double support time and stride variability during walking in PD subjects [1-4]. Additionally, the contralateral gait asymmetry is associated with the chance of a person with PD developing freezing of gait [2,5].

The literature shows that in people with PD, the tremor reduced the upper and lower limbs asymmetry, mainly at higher walking speeds [1]. During the gait cycle, the angular kinematic parameters, such as shoulder and elbow movement, hip flexion and extension, pelvic rotation, knee flexion, plantar, and dorsiflexion of ankle need to be coordinated to conserve energy. The preservation of the range of joint motion results in lower vibrations and lower impact forces during the gait as well as minor compensations during the task. Therefore, the symmetry during gait may result in lower energy expenditure [6-8]. 
Aerobic exercises improve the functionality, mechanics, and energetic parameters in people with PD [9-11]. In this context, Nordic Walking (NW) is an exercise modality that revealed functional improvements in older people with PD [12-15]. The NW is characterized by the use of poles that requires symmetrical and coordinated movements provided by arm participation to move the body forward [16]. Also, the range of upper limb motion is increased using poles [17] changing the muscular synergies, particularly the spatial organization [18] and the magnitude of activation [19] of upper limb muscles in comparison to free walking (FW) [18].

Although the natural history of illness suggests an increasing contralateral asymmetry in PD $[4,20,21]$, the findings are controversial. For example, Delval and colleagues did not observe gait asymmetries [22], whereas the literature showed that the swing time are markedly differently between feet [4]. The asymmetries attributed to cardinal symptoms of PD seem to denote a natural functional difference between the limbs, particularly associated with propulsion and control tasks [23].

While the NW improves functional mobility and independence for PD $[13,14]$, the potential improvement on the contralateral asymmetry after NW intervention remains unknown. Therefore, this study aimed to characterize the contralateral gait asymmetries and to investigate the effects of NW on these asymmetries in individuals with PD. We hypothesized that the kinematic variables during gait at pre-test period should be different between the sides (asymmetric), and that at post-test period, these differences should decrease, resulting in a more symmetrical gait.

\section{Materials and Methods}

\subsection{Experimental Design}

This is an experimental study that evaluated an intentional and non-probabilistic sample of people with Parkinson's disease. We first characterized the gait asymmetry and after tested the NW in the asymmetrical variables. We conducted the study in line with the protocol approved by the Ethics Committee of Research involving human beings from Universidade Federal do Rio Grande do Sul (project number: 69919017.3.0000.5347 and clinical trials ID: NCT03860649). All subjects gave their informed consent for inclusion before they participated in the study.

\subsection{Participants}

We included people with the diagnosis of idiopathic PD, aged 50 to 80 years, 1 to 3 on the Hoehn \& Yahr (H\&Y) scale [24], and physically inactive for at least one month. They should be in medical treatment and should have the ability to understand the verbal instructions to performing the tests. The exclusion criteria are: they should not have history of vertigo, surgeries in lower limbs during the last year, and making use of prostheses in the lower limbs. Further, the participants who undergone deep brain stimulation surgery, who had severe heart diseases or other associated neurological diseases, dementia, and who did not have conditions of ambulation and who got Montreal Cognitive Assessment (MoCA) less than 21 points were excluded [25]. Subjects who missed more than $75 \%$ of classes were excluded. Also, only ambulatory individuals and individuals who were walking without aid on the treadmill were included.

Calculation of the sample size was carried out using the Gpower v.3.1 program. Values of maximal flexion of the knee and maximal abduction of the hip from the study of Ribeiro et al., (2018) were used for the calculation [26], with a level of $5 \%$ and a power of $85 \%$. A number of 14 subjects was estimated, considering the possible sample losses and a good adhesion rate estimated at $70 \%$ [27].

\subsection{Assessment and Intervention Procedures}

All procedures were carried out at the in the Biodynamic sector of the Exercise Research Laboratory (LAPEX). Subjects attended three distinct moments to perform data collection. On the first day, previous evaluation of the individual was performed to verify whether it fit the eligibility criteria. After these initial procedures, the Unified Parkinson's Disease Rating Scale (UPDRS) was performed to determine 
the side more and less affected [28] and H\&Y scale. Subsequently, after $10 \mathrm{~min}$ of rest, the individual performed the six-minute walking test (6MWT) on the ground. After $10 \mathrm{~min}$ of rest, they were familiarized to the treadmill (INBRAMED, model ATL-Inbrasport, Porto Alegre, Brazil), and rating of perceived exertion (Borg Scale) for $15 \mathrm{~min}$ [15].

The kinematic analysis was performed pre and post-intervention of NW. The subjects walked in randomized walking speeds of $0.28 \mathrm{~m} \cdot \mathrm{s}^{-1}$ and $0.83 \mathrm{~m} \cdot \mathrm{s}^{-1}$ for three minutes, and the kinematic data collection was performed at the last minute. The kinematic data collection was carried out by the three-dimensional motion analysis system Vicon (Vicon Motion Capture System-Oxford Instrument Group-USA, 1984), using six infrared cameras $(100 \mathrm{~Hz}$, three cams Bonita with a resolution of $1 \mathrm{MP}$, and three cams T10 with a resolution of 1.3 MP). Thirty-five reflective spherical markers were placed on anatomic landmarks of interest according to the model Plug-in-Gait Full-Body. The three-dimensional reconstruction of the captured kinematic data was obtained automatically by the Vicon NEXUSß1.8.5 software. The system captured a filming space of $4 \mathrm{~m}$ wide, $x 6 \mathrm{~m}$ long, and $3.5 \mathrm{~m}$ high.

The training period lasted 11 weeks, with two weekly sessions, being four sessions of NW technique adaptation and 18 sessions of NW training (22 sessions in total). The volume was determined by the session time in minutes and by the percentage of the distance covered in the 6MWT, which was determined individually for each subject (Equations (1)-(3)) [29]. Therefore, the individuals were divided in three groups of volume coefficient based on the individual capacity of the subjects. These groups include A1: those who walked at 50\% of the 6MWT (coefficient less than 0.85), A2: those who walked at $70 \%$ of the $6 \mathrm{MWT}$ (coefficient between 0.86 and 1.2), and A3: those who walked at $100 \%$ of the $6 \mathrm{MWT}$ (coefficient above 1.2) in the first session. The intensity was based on the subjective intensity of gait that was comfortable, intermediate, maximal, and jog. Comfortable velocity is that speed that person normally walks in the street. The intermediate velocity is the speed between the comfortable and the maximum, and the maximum speed determines how fast as possible the person can walk without running, while the jog is the intensity in which the individuals will run for a short period.

$$
\begin{aligned}
& \text { Volume coefficient }=\text { performed distance } / \text { predicted distance } \\
& \text { Man: predicted distance } \\
& \begin{array}{c}
(\mathrm{m})=493+(2.2 \times \text { height })-(0.93 \times \text { weight })-(5.3 \times \text { age })+17 \mathrm{~m} \\
\text { Woman: predicted distance } \\
(\mathrm{m})=493+(2.2 \times \text { height })-(0.93 \times \text { weight })-(5.3 \times \text { age }) \mathrm{m}
\end{array}
\end{aligned}
$$

The training periodization (Figure 1) was based on [15] and more details can be observed in supplementary material 1 (Tables S1-S3). We conducted the NW training on the athletics track (400 m) of the School of Physical Education, Physical Therapy and Dance (ESEFID) of the Universidade Federal do Rio Grande do Sul (UFRGS). 


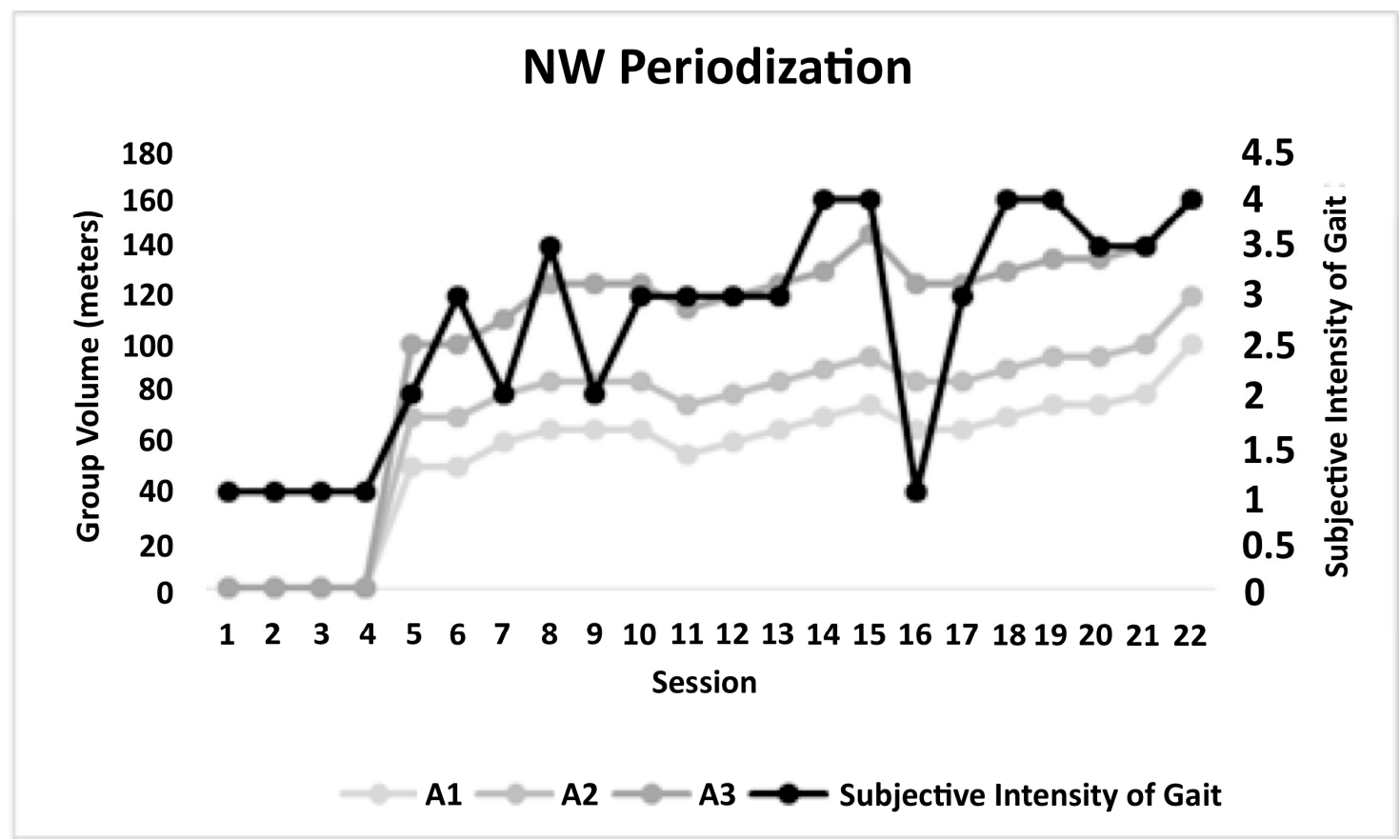

Figure 1. The training volume (grey lines, left vertical scale) is in meters, and intensity (black line, right vertical scale) is in rates of perceived speed during 22 training sessions. The subjective Intensity of Gait is the rate of perceived speed, and the number 1 represents (comfortable), 2 (comfortable and intermediate), 2.5 (intermediate and fast), 3 (comfortable, intermediate, and fast), 3.5 (intermediate and fast) and 4 (comfortable, intermediate, fast, and jog). The individuals included in the Group A1 are those who walk at $50 \%$ of the $6 \mathrm{MWT}$ (coefficient less than 0.85 ), $\mathrm{A} 2$ are those who walk at $70 \%$ of the $6 \mathrm{MWT}$ (coefficient between 0.86 and 1.2), and A3 are those walking at $100 \%$ of the $6 \mathrm{MWT}$ (coefficient above 1.2) in the fifth session.

\subsection{Data Analysis}

The kinematic analysis was performed using the Nexus software [15]. Firstly, we investigate if the subjects presented any asymmetries of maximal flexion of hip, knee, and ankle, abduction ROM of hip and the maximal abduction of hip and flexion and extension maximal of knee on touch down and, stance time(s), relative stance time (\%) and double stance time(s). After, we tested the effect of NW on the asymmetrical variables. The angles were determined by software VICON NEXUS@1.8, that use Euler calculations, all lower and upper body angles are calculated in rotation order YXZ, except for ankle angles, which are calculated in order YZX (available on Plug-in Gait Reference Guide).

The spatiotemporal variables were determined from the touch down and takeoff by 10 strides in the gait cycle. The mean of 10 strides was used to calculated angle and spatiotemporal outcomes. The data was exported from Vicon NEXUS ${ }^{\circledR}$ 1.8.5 software and processed in the LabVIEW software (National Instruments 8.5). The symmetry between the segments was considered when no statistical differences were observed in the parameters measured bilaterally [23].

\subsection{Statistical Analysis}

We used descriptive analysis to report the results (mean and confidence interval Wald 95\%). The Generalized Estimating Equations (GEE) was used to characterize the gait asymmetries. When $p<0.05$, the variables were considered asymmetric. Additionally, GEE was used to test the main effects of NW in asymmetrical variables, and the Bonferroni post hoc test was performed to identify the significant differences at $\alpha<0.05$. Also, the effect size (ES) was calculated using the Hedges' g considering trivial $(<0.20)$, small $(0.20-0.49)$, moderate $(0.50-0.79)$, large $(>0.80)$, and too large $(>1.30)$ effects between pre and post-tests at more affected and less affected segments in the asymmetrical 
variables [30,31]. Statistical analysis was performed by a highly trained researcher who was blinded to the participants, using SPSS software (Statistical Package for Social Sciences, version 21.0).

\section{Results}

A total of 14 participants with idiopathic PD were included in the study. Individual characteristics of the sample are shown in Table 1.

Table 1. Characteristics of the subjects.

\begin{tabular}{cc}
\hline Variable & Mean (Standard Deviation) \\
\hline Total subjects (male/female) & $14(7 / 7)$ \\
Gender (female/male) & $7 / 7$ \\
Age (years) & $66.8( \pm 9.6)$ \\
Disease duration (years) & $7.2( \pm 5.4)$ \\
UPDRS (points) & $12.2( \pm 6.1)$ \\
H \& Y & $1.5(1-3)$ \\
MoCA & $26.6(2.2)$ \\
Lower limb length $(\mathrm{m})$ & $0.89(0.05)$ \\
Body mass $(\mathrm{kg})$ & $64.5( \pm 23.5)$ \\
Height $(\mathrm{m})$ & $1.7( \pm .86)$ \\
\hline
\end{tabular}

The results showed asymmetries in baseline with a significant difference for maximum knee flexion at $0.28 \mathrm{~m} \cdot \mathrm{s}^{-1}$. Time-condition interaction analysis $(p=0.007)$ showed that the improvement occurred only in the less affected limb [ $p<0.001$ (ES: 0.82)] when compared to the more affected limb (Figure 2A and Table 2).
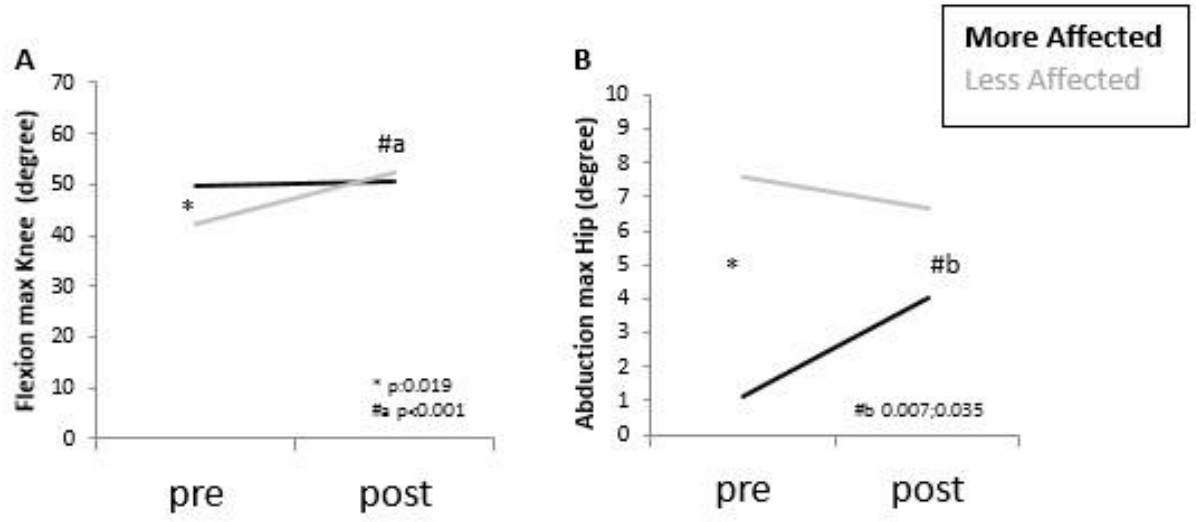

Figure 2. Asymmetric variables between less affected (grey line) and more affected (black line) limbs, pre and post-intervention at $0.28 \mathrm{~m} \cdot \mathrm{s}^{-1}$, based in post hoc values. *: Difference between conditions on pre; (A) Difference between pre and post in the less affected side; (B) Difference between pre and post in both groups. 
Table 2. Mean, confidence interval, minimal ( $\mathrm{min}$ ) and maximal (max) values, and effect size of Maximal angular of flexion and abduction in more and less affected segments at $0.28 \mathrm{~m} \cdot \mathrm{s}^{-1}$

\begin{tabular}{|c|c|c|c|c|c|c|c|c|c|c|}
\hline & & \multicolumn{2}{|c|}{ PRE } & \multicolumn{2}{|c|}{ POST } & \multirow{2}{*}{\multicolumn{3}{|c|}{$p$-Value }} & \multirow[b]{3}{*}{$\begin{array}{l}\text { ES More } \\
\text { Affected }\end{array}$} & \multirow[b]{3}{*}{$\begin{array}{l}\text { ES Less } \\
\text { Affected }\end{array}$} \\
\hline & & More Affected & Less Affected & More Affected & Less Affected & & & & & \\
\hline & $\begin{array}{c}\text { Speed } \\
\left(\mathrm{m} \cdot \mathrm{s}^{-1}\right)\end{array}$ & $\begin{array}{c}\text { Mean } \\
(\max ; \min )\end{array}$ & $\begin{array}{c}\text { Mean } \\
(\max ; \min )\end{array}$ & $\begin{array}{c}\text { Mean } \\
(\max ; \min )\end{array}$ & $\begin{array}{c}\text { Mean } \\
\text { (max; } \min )\end{array}$ & $\mathrm{T}$ & $\mathrm{C}$ & $\mathrm{T}^{*} \mathrm{C}$ & & \\
\hline Flexion & - & - & - & - & - & - & - & - & - & - \\
\hline $\begin{array}{l}\text { Knee (degree) } \\
\text { Abduction }\end{array}$ & 0.28 & $49.9(45.7 ; 54.1)$ & $42.3(35.7 ; 49.0)$ & $50.8(46.2 ; 55.4)$ & $52.3(47.3 ; 57.3)$ & 0.012 * & 0.236 & 0.007 * & 0.10 & 0.82 \\
\hline Hip (degree) & 0.28 & $1.1(-1.9 ; 4.1)$ & $7.6(4.7 ; 10.5)$ & $4.00(2.04 ; 5.96)$ & $6.7(4.7 ; 8.6)$ & 0.329 & 0.007 * & 0.040 * & 0.56 & 0.19 \\
\hline
\end{tabular}


Additionally, there was asymmetry in the maximal hip abduction with time-condition interaction (Figure 2B and Table 2) at speed $0.28 \mathrm{~m} \cdot \mathrm{s}^{-1}(p=0.040)$. The maximal hip abduction was increased between pre and post in both groups $[p=0.035$ (ES $=0.56$ more affected limb)] and $[p=0.007$ (ES: 0.19 less affected limb)]. The other variables did not show asymmetries and are represented in supplementary material 2 .

\section{Discussion}

The main purpose of this study was to characterize the gait asymmetries and then investigate the effects of NW training in the asymmetries variables. Before the intervention, the individuals with mild PD walking at $0.28 \mathrm{~m} \cdot \mathrm{s}^{-1}$ showed asymmetries only in maximal knee flexion and maximal hip abduction. We refuted the hypothesis because most movements were symmetric in the baseline. On the other hand, secondary asymmetries were interestingly found at the knee and hip joints. The NW training was able to improve these parameters, becoming more symmetrical in these parameters after the intervention.

In PD, the basal ganglia dysfunction contributes to more significant gait disturbances and symptoms are directly associated with right or left cerebral hemisphere, though mechanisms responsible for this left-right coordination are not fully understood [32,33]. Additionally, PD asymmetry can be explained for a reduced number of neurons in one side of substantia nigra [34]. However, the asymmetrical side might be merely coincidental, and in the early stage, the degeneration is lower [35]. In our study, the asymmetry between the sides was considered when the valued was less than 5\% in the statistic test [23]. Probably, the general symmetry observed in the pre-test seems to be explained due to mild stage (H\&Y median: 1.5 points) of $\mathrm{PD}$ and phase of medication "ON" utilized in the present study [26,36]. Furthermore, the disease duration is $7.3 \pm 5.4$ years, and, at this stage of the disease, the people with PD have a similar likelihood of unilateral and bilateral motor impairments [37]. One crucial question raised by these findings is the importance of gait analysis for detecting the motor asymmetry as a screening evaluation $[38,39]$. In our study, we consider gait asymmetry based on the study [23]. Also, the literature describes that gait asymmetry is related to the increase in freezing [32]. However, it is necessary to acknowledge that our PD subjects did not experience freezing of gait during the walking evaluation. Therefore, the symmetry is justified on baseline condition.

Although most kinematic variables were symmetric bilaterally, the maximum knee flexion and hip abduction at $0.28 \mathrm{~m} \cdot \mathrm{s}^{-1}$ were asymmetric before the intervention. After the intervention, both variables became symmetric. The literature shows that exercise can improve Parkinson's gait performance [40]. In [41], the authors observed that NW was able to increase knee power during gait, in the more and less affected side [41]. In the present study, we observed higher maximal knee flexion in the less affected size, indicating that after NW intervention, the role of compensating the impaired movement was reduced in the less affected knee during the gait cycle. We also considered that the increase in range of knee motion might be attributed to muscle regulation as a result of lower antagonist muscle stiffness, or even because of increasing muscular strength and power of the knee flexion agonist muscles. Although the main component of this increase remains unknown, greater freedom of joint movement contributes to a more symmetrical gait and a lower risk of falls.

Higher values of maximal hip abduction and symmetry between sides were found after NW intervention in our subjects. In line with these findings, [42] showed that after treadmill training, PD subjects improve the angle of hip abduction of the dominant and non-dominant sides [42]. The higher pelvic rotation could explain the higher angle of hip abduction. However, no rotational movements were measured in this study. The symmetry found in the hip abduction found out after the training period may contribute to functional mobility due to reduced energy expenditure and lower risk of falling. Also, the larger range of hip abduction motion during gait may be related to reduced muscle and joint stiffness. Although Nordic walking (NW) uses stick support, the gains acquired from training seem to benefit the free-walking pattern of subjects with PD. Besides the improvement, the maximal abduction motion observed in our study (4 to 7 degrees) is still lower than 
healthy people, approximately 10 degrees [6]. Another important point to highlight is that our test was measured on a treadmill, and the angular and spatiotemporal variables can be changed when compared with free walking [43]. We suggest more studies that compared gait asymmetries in these conditions, and to obtain more details, it is important to do correlations with oxygen consumption and anatomical/structural symmetry of the lower limbs [44].

The NW is an intervention where the action from upper and lower limbs is required, resulting in a synergy between upper and lower limb muscles. The poles promote more considerable support base and weight discharge [45]. These characteristics can improve the maximal ROM of the knee and hip during gait of people with PD. Therefore, the improvement in the quality of movements during gait is critical in the daily life of this population. This study has some limitations, including: (1) it did not have a control group, (2) the control regarding the physical activity quantity from the participants on baseline (very active, active, inactive, and sedentary), and (3) we did not evaluate the freezing of gait, which could have a better detection of gait asymmetry.

\section{Conclusions}

The hypothesis was not supported, and our findings demonstrate that subjects with mild PD had symmetric gait before the intervention, except for maximal hip abduction and maximal knee flexion. NW enhanced the kinematic pattern of knee and hip joints during free-walking on the treadmill, and the more affected and less affected side became symmetric. The improvement of the range of knee and hip motion is crucial to improve the functionality of subjects with PD.

Supplementary Materials: The following are available online at http://www.mdpi.com/2073-8994/11/12/1481/s1, TIDier items S1: Nordic Walking intervention, Table S4: Mean, confidence interval and statistical significance of maximal flexion and abduction variables on 0.28 and $0.83 \mathrm{~m} \cdot \mathrm{s}^{-1}$. Table S5: Mean, confidence interval and statistical significance and range of motion of more and less affected segments on 0.28 and $0.83 \mathrm{~m} \cdot \mathrm{s}^{-1}$. Table S6: Mean, confidence interval and statistical significance of spatiotemporal variables on 0.28 and $0.83 \mathrm{~m} \cdot \mathrm{s}^{-1}$.

Author Contributions: Conception of project, A.P.J.Z. and L.A.P.-T.; Organization, A.P.J.Z. and L.A.P.-T.; Execution, A.P.J.Z., M.Z.C. and V.F.M.; Statistical analysis, A.P.J.Z. and V.F.M.; Manuscript Preparation, A.P.J.Z., F.G.M., E.S.d.S. and L.A.P.-T.; Writing of the first draft, A.P.J.Z.; Review and Critique, A.P.J.Z., F.G.M., E.S.d.S., M.Z.C., V.F.M., E.P.-M., A.N.H. and L.A.P.-T.

Funding: This research was funded by Coordenação de Aperfeiçoamento de Pessoal de Nível Superior-Brasil (CAPES)-Finance Code 001.

Conflicts of Interest: The authors declare that they have no conflicts of interest relevant to the content of this review.

\section{References}

1. Morris, S.; Morris, M.E.; Iansek, R. Reliability of measurements obtained with the Timed "Up \& Go" test in people with Parkinson disease. Phys. Ther. 2001, 81, 810-818. [CrossRef] [PubMed]

2. Frazzitta, G.; Pezzoli, G.; Bertotti, G.; Maestri, R. Asymmetry and freezing of gait in parkinsonian patients. J. Neurol. 2013, 260, 71-76. [CrossRef] [PubMed]

3. Williams, A.J.; Peterson, D.S.; Earhart, G.M. Gait coordination in Parkinson disease: Effects of step length and cadence manipulations. Gait Posture 2013, 38, 340-344. [CrossRef] [PubMed]

4. Martinez, M.; Villagra, F.; Castellote, J.M.; Pastor, M.A. Kinematic and Kinetic Patterns Related to Free-Walking in Parkinson's Disease. Sensors 2018, 18, 4224. [CrossRef]

5. Boonstra, T.A.; van der Kooij, H.; Munneke, M.; Bloem, B.R. Gait disorders and balance disturbances in Parkinson's disease: Clinical update and pathophysiology. Curr. Opin. Neurol. 2008, 21, 461-471. [CrossRef]

6. Saunders, J.B.D.M.; Inman, V.T.; Eberhart, H.D. The major determinants in normal and pathological gait. J. Bone Jt. Surg. Am. 1953, 35, 543-558. [CrossRef]

7. Cavagna, A.; Thys, H.; Zamboni, A. The sources of external work in level walking and running. J. Physiol. 1976, 262, 639-657. [CrossRef]

8. Bianchi, L.; Angelini, D.; Orani, G.P.; Lacquaniti, F. Kinematic coordination in human gait: Relation to mechanical energy cost. J. Neurophysiol. 1998, 79, 2155-2170. [CrossRef] 
9. Goodwin, V.A.; Richards, S.H.; Taylor, R.S.; Taylor, A.H.; Campbell, J.L. The effectiveness of exercise interventions for people with Parkinson's disease: A systematic review and meta-analysis. Mov. Disord. 2008, 23, 631-640. [CrossRef]

10. Shu, H.F.; Yang, T.; Yu, S.X.; Huang, H.D.; Jiang, L.L.; Gu, J.W.; Kuang, Y.Q. Aerobic exercise for Parkinson's disease: A systematic review and meta-analysis of randomized controlled trials. PLoS ONE 2014, 9, e100503. [CrossRef]

11. Hubble, R.P.; Naughton, G.; Silburn, P.A.; Cole, M.H. Trunk Exercises Improve Gait Symmetry in Parkinson Disease: A Blind Phase II Randomized Controlled Trial. Am. J. Phys. Med. Rehabil. 2018, 97, 151-159. [CrossRef] [PubMed]

12. Cugusi, L.; Manca, A.; Dragone, D.; Deriu, F.; Solla, P.; Secci, C.; Monticone, M.; Mercuro, G. Nordic Walking for the Management of People With Parkinson Disease: A Systematic Review. PMER 2017, 9, 1157-1166. [CrossRef]

13. Monteiro, E.P.; Franzoni, L.T.; Cubillos, D.M.; de Oliveira Fagundes, A.; Carvalho, A.R.; Oliveira, H.B.; Pantoja, P.D.; Schuch, F.B.; Rieder, C.R.; Martinez, F.G.; et al. Effects of Nordic walking training on functional parameters in Parkinson's disease: A randomized controlled clinical trial. Scand. J. Med. Sci. Sports 2017, 27, 351-358. [CrossRef] [PubMed]

14. Franzoni, L.T.; Monteiro, E.P.; Oliveira, H.B.; da Rosa, R.G.; Costa, R.R.; Rieder, C.; Martinez, F.G.; Peyré-Tartaruga, L.A. A 9-week Nordic and free walking improve postural balance in Parkinson's disease. Sports Med. Int. Open 2018, 2, 28-34. [CrossRef] [PubMed]

15. Gomeñuka, N.A.; Oliveira, H.B.; Silva, E.S.; Costa, R.R.; Kanitz, A.C.; Liedtke, G.V.; Schuch, F.B.; Peyré-Tartaruga, L.A. Effects of Nordic walking training on quality of life, balance and functional mobility in elderly: A randomized clinical trial. PLoS ONE 2019, 14, e0211472. [CrossRef] [PubMed]

16. Arcila, D.M.C.; Monteiro, E.P.; Gomeñuka, N.A.; Peyré-Tartaruga, L.A. Metodologia e Didática Pedagógica aplicada ao ensino da Caminhada Nórdica e Livre para pessoas com Doença de Parkinson I [Methodology and pedagogical didactics applied to the education of nordic walking and free walking for people with parkinson's disease I]. Cad. RBCE 2018, 8, 72-83.

17. Pellegrini, B.; Peyré-Tartaruga, L.A.; Zoppirolli, C.; Bortolan, L.; Savoldelli, A.; Minetti, A.E.; Schena, F. Mechanical energy patterns in Nordic walking: Comparisons with conventional walking. Gait Posture 2017, 51, 234-238. [CrossRef]

18. Boccia, G.; Zoppirolli, C.; Bortolan, L.; Schena, F.; Pellegrini, B. Shared and task-specific muscle synergies of Nordic walking and conventional walking. Scand. J. Med. Sci. Sports 2018, 28, 905-918. [CrossRef]

19. Pellegrini, B.; Peyré-Tartaruga, L.A.; Zoppirolli, C.; Bortolan, L.; Bacchi, E.; Figard-Fabre, H.; Schena, F. Exploring muscle activation during Nordic walking: A comparison between conventional and uphill walking. PLoS ONE 2015, 10, e0138906. [CrossRef]

20. Miller, R.A.; Thaut, M.H.; McIntosh, G.C.; Rice, R.R. Components of EMG symmetry and variability in parkinsonian and healthy elderly gait. Electroencephalogr. Clin. Neurophysiol. 1996, 101, 1-7. [CrossRef]

21. Morris, M.E.; Huxham, F.; McGinley, J.; Dodd, K.; Iansek, R. The biomechanics and motor control of gait in Parkinson disease. Clin. Biomech. 2001, 16, 459-470. [CrossRef]

22. Delval, A.; Salleron, J.; Bourriez, J.L.; Bleuse, S.; Moreau, C.; Krystkowiak, P.; Defebvre, L.; Devos, P.; Duhamel, A. Kinematic angular parameters in PD: Reliability of joint angle curves and comparison with healthy subjects. Gait Posture 2008, 28, 495-501. [CrossRef] [PubMed]

23. Sadeghi, H.; Allard, P.; Prince, F.; Labelle, H. Symmetry and limb dominance in able-bodied gait: A review. Gait Posture 2000, 12, 34-45. [CrossRef]

24. Mehrholz, J.; Kugler, J.; Storch, A.; Pohl, M.; Hirsch, K.; Elsner, B. Treadmill training for patients with Parkinson Disease. An abridged version of a Cochrane Review. Eur. J. Phys. Rehabil. Med. 2016, 52, 704-713. [PubMed]

25. Tumas, V.; Borges, V.; Ballalai-Ferraz, H.; Zabetian, C.P.; Mata, I.F.; Brito, M.M.C.; Foss, M.P.; Novaretti, N.; Santos-Lobato, B.L. Some aspects of the validity of the Montreal Cognitive Assessment (MoCA) for evaluating cognitive impairment in Brazilian patients with Parkinson's disease. Dement. Neuropsychol. 2016, 10, 333-338. [CrossRef] [PubMed]

26. Ribeiro, T.S.; de Sousa, A.C.; de Lucena, L.C.; Santiago, L.M.M.; Lindquist, A.R.R. Does dual task walking affect gait symmetry in individuals with Parkinson's disease? Eur. J. Physiother. 2018, 21, 8-14. [CrossRef]

27. O'neal, H.A.; Blair, S.N. Enhancing Adherence in Clinical Exercise Trials. Quest 2001, 53, 310-317. [CrossRef] 
28. Raciti, L.; Nicoletti, A.; Mostile, G.; Bonomo, R.; Contrafatto, D.; Dibilio, V.; Luca, A.; Sciacca, G.; Cicero, C.E.; Vasta, R.; et al. Validation of the UPDRS section IV for detection of motor fluctuations in Parkinson's disease. Park. Relat. Disord. 2016, 27, 98-101. [CrossRef]

29. Enright, P.L.; McBurnie, M.A.; Bittner, V.; Tracy, R.P.; McNamara, R.; Arnold, A.; Newman, A.B. The 6-min walk test: A quick measure of functional status in elderly adults. Chest 2003, 123, 387-398. [CrossRef]

30. Rosenthal, J.A. Qualitative Descriptors of Strength of Association and Effect Size. J. Soc. Serv. Res. 1996, 21, 37-59. [CrossRef]

31. Espirito-santo, H.; Daniel, F. Calcular e apresentar tamanhos do efeito em trabalhos científicos (1): As limitações do $p<0.05$ na análise de diferenças de médias de dois grupos. Rev. Port. Invest. Comp. Soc. 2015, 1, 3-6.

32. Plotnik, M.; Giladi, N.; Balash, Y.; Peretz, C.; Hausdorff, J.M. Is freezing of gait in Parkinson's disease related to asymmetric motor function? Ann. Neurol. 2005, 57, 656-663. [CrossRef] [PubMed]

33. Lee, E.Y.; Sen, S.; Eslinger, P.J.; Wagner, D.; Kong, L.; Lewis, M.M.; Du, G.; Huang, X. Side of motor onset is associated with hemisphere-specific memory decline and lateralized gray matter loss in Parkinson's disease. Park. Relat Disord 2015, 21, 465-470. [CrossRef] [PubMed]

34. Djaldetti, R.; Ziv, I.; Melamed, E. The mystery of motor asymmetry in Parkinson's disease. Lancet Neurol. 2006, 5, 796-802. [CrossRef]

35. Mirelman, A.; Bonato, P.; Camicioli, R.; Ellis, T.D.; Giladi, N.; Hamilton, J.L.; Hass, C.J.; Hausdorff, J.M.; Pelosin, E.; Almeida, Q.J. Gait impairments in Parkinson's disease. Lancet Neurol. 2019, 18, 697-708. [CrossRef]

36. Yogev, G.; Plotnik, M.; Peretz, C.; Giladi, N.; Hausdorff, J.M. Gait asymmetry in patients with Parkinson's disease and elderly fallers: When does the bilateral coordination of gait require attention? Exp. Brain Res. 2007, 177, 336-346. [CrossRef]

37. Schenkman, M.L.; Clark, K.; Xie, T.; Kuchibhatla, M.; Shinberg, M.; Ray, L. Spinal movement and performance of a standing reach task in participants with and without Parkinson disease. Phys. Ther. 2001, 81, 1400-1411. [CrossRef]

38. Djurić-Jovičić, M.; Belić, M.; Stanković, I.; Radovanović, S.; Kostić, V.S. Selection of gait parameters for differential diagnostics of patients with de novo Parkinson's disease. Neurol. Res. 2017, 39, 853-861. [CrossRef]

39. Meyer, C.; Killeen, T.; Easthope, C.S.; Curt, A.; Bolliger, M.; Linnebank, M.; Zörner, B.; Filli, L. Familiarization with treadmill walking: How much is enough? Sci. Rep. 2019, 9, 5232. [CrossRef]

40. Ni, M.; Hazzard, J.B.; Signorile, J.F.; Luca, C. Exercise Guidelines for Gait Function in Parkinson's Disease: A Systematic Review and Meta-analysis. Neurorehabil. Neural Repair 2018, 32, 872-886. [CrossRef]

41. Zhou, L.; Gougeon, M.A.; Nantel, J. Nordic Walking Improves Gait Power Profiles at the Knee Joint in Parkinson's Disease. J. Aging Phys. Act. 2018, 26, 84-88. [CrossRef] [PubMed]

42. Luna, N.M.S.; Lucareli, P.R.G.; Sales, V.C.; Speciali, D.; Alonso, A.C.; Peterson, M.D.; Rodrigues, R.B.M.; Fonoffc, E.T.; Barbosac, E.R.; Teixeira, M.J.; et al. Treadmill training in Parkinson's patients after deep brain stimulation: Effects on gait kinematic. Neurorehabilitation 2018, 42, 149-158. [CrossRef] [PubMed]

43. Malatesta, D.; Canepa, M.; Fernandez, A.M. The effect of treadmill and overground walking on preferred walking speed and gait kinematics in healthy, physically active older adults. Eur. J. Appl. Physiol. 2017, 117, 1833-1843. [CrossRef] [PubMed]

44. Seminati, E.; Nardello, F.; Zamparo, P.; Ardigó, L.P.; Faccioli, N.; Minetti, A.E. Anatomically Asymmetrical Runners Move More Asymmetrically at the Same Metabolic Cost. PLoS ONE 2013, 8, e74134. [CrossRef] [PubMed]

45. Dziuba, A.K.; Żurek, G.; Garrard, I.; Wierzbicka-Damska, I. Parameters in lower limbs during natural walking and Nordic walking at different speeds. Acta Bioeng. Biomech. 2015, 17, 95-101. [PubMed]

(C) 2019 by the authors. Licensee MDPI, Basel, Switzerland. This article is an open access article distributed under the terms and conditions of the Creative Commons Attribution (CC BY) license (http://creativecommons.org/licenses/by/4.0/). 